\title{
Identification of genetic defects underlying FVII deficiency in 10 patients belonging to eight unrelated families of the North provinces from Tunisia
}

Hejer Elmahmoudi ${ }^{*}$, Fatma Ben-lakhal ${ }^{2}$, Wijden Elborji ${ }^{2}$, Asma Jlizi ${ }^{1}$, Kaouther Zahra ${ }^{2}$, Rim Sassi ${ }^{1}$, Moez Zorgan ${ }^{2}$, Balkis Meddeb², Amel Elgaaied Ben Ammar ${ }^{1}$ and Emna Gouider ${ }^{2}$

\begin{abstract}
Inherited factor VII (FVII) deficiency is a rare disorder characterized by a bleeding phenotype varying from mild to severe. To date, more than 200 mutations have been described along the F7 gene encoding for FVII. The aim of this study was the identification of genetic defects underlying FVII deficiency in 10 patients belonging to eight unrelated families of the North provinces from Tunisia. Mutation detection was performed by sequencing the whole F7 gene coding region, exon-intron boundaries and about 400 bp of the promoter region. We identified 5 mutations in five unrelated families; the novel p.F328Y mutation and the reported mutations: p.R304Q, p.M298I, IVS1aG > A and p.G-39G. For the remaining 5 patients we didn't identified any mutations using PCR/Sequencing protocol. In conclusion, this study represents the first comprehensive molecular series of FVII deficiency affected patients in Tunisia from the North. We will try in the future to continue the molecular study for Tunisian patients from Center and South provinces in order to have a complete idea about the FVII deficiency mutational profile in our country.
\end{abstract}

Virtual slides: The virtual slide(s) for this article can be found here: http://www.diagnosticpathology.diagnomx.eu/ vs/1288044089753085

Keywords: FVII deficiency, F7 gene, Mutations, Polymorphisms, Tunisia

\section{Introduction}

Factor VII deficiency is an inherited rare bleeding disorder, which results from decreased or absence of coagulation FVII. Factor VII deficiency is transmitted according the autosomic way and affects $1 / 500000$ population [1]. The clinical features are heterogeneous, ranging from severe life-threatening hemorrhages, such as cerebral, gastrointestinal, and joint hemorrhages, to miscellaneous minor bleeding. The severity isn't correlated with FVII activities residual levels. FVII is a serine protease which accelerates the prothrombin conversion. F7 gene which encodes coagulation molecule responsible for blood coagulation was discovered in 1987. It is located on chromosome 13q34 and contained 9 exons. More than 200 mutations were

\footnotetext{
* Correspondence: hejer.abdalah@gmail.com

'Laboratory of Genetics, Immunology and Human Pathologies, Tunis, Tunisia Full list of author information is available at the end of the article
}

identified in the entire $F 7$ gene, especially punctual mutations. The genotype-phenotype relationship in FVII deficiency is variable $[1,2]$. The clinical phenotype in patients is generally more severe in homozygous or compoundheterozygous than heterozygous patients [2]. In Tunisia, according to the World Federation of Hemophilia (WFH) global survey 2009 [3], 15 patients with FVII deficiency are reported. Twelve of them belong to our Hemophilia Treatment Center of Aziza Othaman. The reported data concerning FVII deficiency in Tunisia were interested in the determination of some polymorphisms frequencies or in the study of molecular defect only in Tunisian Jewish patients [4-6]. The main objective of this study has been to identify the molecular defects in the $F 7$ gene of Tunisian patients and explain the phenotype data of our patients based on their genotypes. In our knowledge this
C Biomed Central

(c) 2012 Elmahmoudi et al.; licensee BioMed Central Ltd. This is an Open Access article distributed under the terms of the Creative Commons Attribution License (http://creativecommons.org/licenses/by/2.0), which permits unrestricted use, distribution, and reproduction in any medium, provided the original work is properly cited. 
is the first report of molecular defect in Arab Tunisian patients with FVII deficiency.

\section{Material and methods Patients}

The studied subjects belonging to Hemophilia Treatment Center of Aziza Othmana, Tunis were recruited between 2010 and 2011. In order to identify the molecular defects of $F 7$ gene, we included 10 patients (women-6, men-4) from 8 unrelated families with factor VII activities (FVII: C) ranging from $2 \%$ to $40 \%$. Their age ranges between 14 and 64 years old. The hemorrhagic symptoms are presented in Table 1.

\section{Methods}

\section{DNA extraction and amplification}

An informed consent was obtained from each patient prior to blood collection. DNA was extracted from white blood cells by standard phenol chloroform extraction method [7]. PCR primers were used for amplification of the whole coding regions, the exon-intron boundaries and the 5 ' flanking region containing the promoter of $F 7$ gene [8]. PCR was carried out in a $25 \mathrm{ml}$ reaction volume in ABI thermal cycle (Perkin-Elmer Applied Biosystems, Foster City, CA, USA).

\section{Sequencing}

Amplified regions were sequenced using ABI Dye Terminator Cycle Sequencing (Perkin-Elmer Applied Biosystems, Foster City, CA, USA) and analyzed using a capillary sequencer Genetic Analyser ABI PRISM310 (Perkin-Elmer Applied Biosystems, Foster City, CA, USA). Results were analyzed using BLAST program (http://www.ncbi.nlm.nih.gov/blast) against the normal F7 gene sequence and the mutations were compared with the factor VII mutation database available at http:// europium.csc.mrc.ac.uk/.

\section{Results}

\section{Clinical data}

The symptoms observed in our patients are epistaxis, menorrhagia, bruising and metrroragia. The unique episode of hematoma was observed in one woman after trauma. No patients had experienced intracranial hemorrhage (Table 1). Only five patients are treated with prothrombin complex concentrate (PCC).

\section{Molecular data}

Ten fragments corresponding to putative promoter, coding regions and exon-intron boundaries of the $F 7$ gene were screened for mutation by PCR/sequencing method. A list of potentially pathogenic mutations and polymorphisms of the $F 7$ gene is shown in Table 1. The position of mutations and polymorphisms are based on the original F7 gene reported by O'Hara [9].

We identified 5 different mutations in 5 unrelated patients. The mutations are composed of three missense mutations and 2 splicing site mutations. Among them one mutation is novel.

\section{Table 1 Phenotype and genotype data of Tunisian patients with FVII deficiency}

\begin{tabular}{|c|c|c|c|c|c|c|c|c|c|c|}
\hline Family & Patient & Age & Symptoms & FVII: C & Mutation & Location & Domain & Type & Genotype & Polymorphism \\
\hline 1 & 1 & 1992 & $\begin{array}{l}\text { Epistaxis, gastrointestinal, } \\
\text { dental extraction }\end{array}$ & $23 \%$ & p.F328Y* & Exon 8 & Cataltytic & Missense & Heterozygous & M1M1, P0/P0, A1/A1,H5 \\
\hline 2 & 2 & 1996 & $\begin{array}{l}\text { Epistaxis, dental } \\
\text { extraction, gingival, } \\
\text { menorrhagia }\end{array}$ & $26 \%$ & p.M2981 & Exon 8 & Cataltytic & Missense & Heterozygous & $\mathrm{M} 1 \mathrm{M} 2, \mathrm{P} 0 / \mathrm{P} 10, \mathrm{~A} 1 / \mathrm{A} 2, \mathrm{H} 5$ \\
\hline 3 & 3 & 1992 & Asymptomatic & ND & p.R304Q & Exon 8 & Cataltytic & Missense & Homozygous & $\mathrm{M} 1 \mathrm{M1} 1, \mathrm{P} 0 / \mathrm{P} 0, \mathrm{~A} 1 / \mathrm{A} 1, \mathrm{H} 5$ \\
\hline 4 & 4 & 1991 & $\begin{array}{l}\text { Hemarthroses, } \\
\text { gingival, menorrhagia }\end{array}$ & $40 \%$ & IVS1a $+5 \mathrm{G}>\mathrm{A}$ & Intron 1a & Propeptide & Splicing & Heterozygous & $\mathrm{M} 1 \mathrm{M} 1, \mathrm{P} 0 / \mathrm{P} 0, \mathrm{~A} 1 / \mathrm{A} 1, \mathrm{H} 5$ \\
\hline 5 & 5 & 1985 & $\begin{array}{l}\text { Epistaxis, dental } \\
\text { extraction, gingival }\end{array}$ & ND & p.G-39G & Exon $1 \mathrm{~b}$ & Propeptide & Splicing & Heterozygous & M1M1, P0/P10, A1/A2,H5 \\
\hline 6 & $\begin{array}{l}6 \\
7\end{array}$ & $\begin{array}{l}1980 \\
1974\end{array}$ & $\begin{array}{l}\text { Epistaxis, dental } \\
\text { extraction, gingival, } \\
\text { Menorrhagia, epistaxis }\end{array}$ & $\begin{array}{l}2.5 \% \\
5 \%\end{array}$ & ND & & & & & M1M1, P0/P0, A1/A1,H5 \\
\hline 7 & $\begin{array}{l}8 \\
9\end{array}$ & $\begin{array}{l}1990 \\
1985\end{array}$ & $\begin{array}{l}\text { Menorrhagia, epistaxis } \\
\text { dental extraction, } \\
\text { gingival }\end{array}$ & $\begin{array}{l}4 \% \\
4 \%\end{array}$ & ND & & & & & $\mathrm{M} 1 \mathrm{M} 1, \mathrm{P} 0 / \mathrm{P0}, \mathrm{A} 1 / \mathrm{A} 1, \mathrm{H} 5$ \\
\hline 8 & 10 & 1963 & Menorrhagia, epistaxis & $5 \%$ & ND & & & & & $\mathrm{M} 1 \mathrm{M1} 1, \mathrm{P} 0 / \mathrm{P0}, \mathrm{A} 1 / \mathrm{A} 1, \mathrm{H} 7$ \\
\hline
\end{tabular}

*Novel mutation.

Nucleotide numbers are based on the full sequence published by O'hara et al 1987 using the A of the ATG initiator methionine as +1 . Numbering of the amino acids is based on Genebank file NM-000131. Methionine is numbered as -60 .

Polymorphisms: M1: Arg at position 353, M2: Gln at position 353. P0: no insertion of 10 bp at position-323 in promoter, P10: insertion of 10 bp at position-323 in promoter. $\mathrm{A} 1$ : nt $\mathrm{C}$ at position -122 in promoter, $\mathrm{A} 2$ : $\mathrm{nt} \mathrm{T}$ at position -122 in promoter.

ND: not determined. 


\section{Missense mutations $(n=3)$}

The 3 missense mutations were detected within the F7 gene (Figure 1) in exon 8; a novel heterozygous mutation p.F328Y (TTC $\rightarrow$ TAC) in patient 1 , a reported heterozygous p.M298I (ATG $\rightarrow$ ATA) in patient 2 and a reported homozygous $\mathrm{G}>\mathrm{A}$ transition leading to p.R304Q substitution $(\mathrm{CGG} \rightarrow \mathrm{CAG}$ ) in patient 3 (Table 1 ).

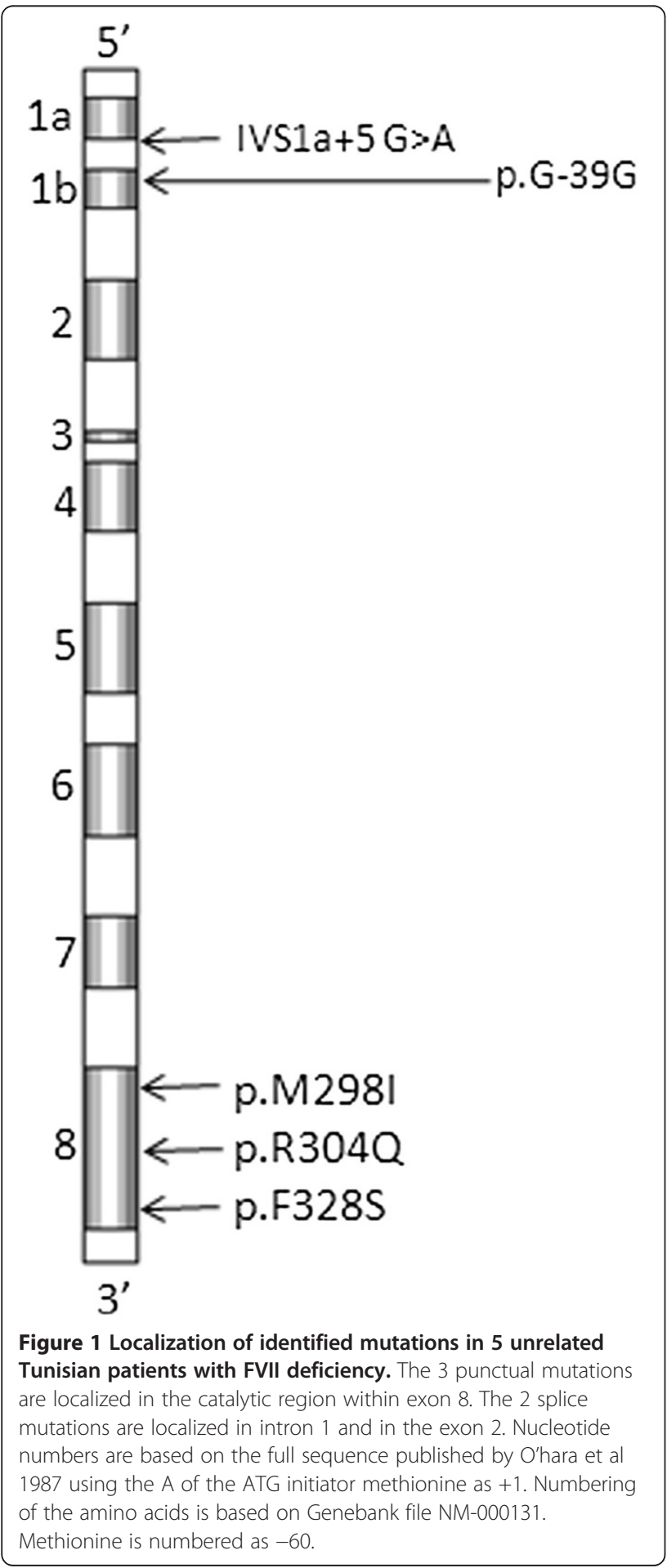

Splicing site mutations $(n=2)$

Sequencing of exon/intron regions using genomic DNA revealed a heterozygous splicing donor site mutation IVS1a $+5 \mathrm{G}>\mathrm{A}$ (patient 4) and one silent mutation p.G-39G (GGC > GGT) occurring in the heterozygous state (patient 5). Since the silent mutation is located in +2 within the exon $1 \mathrm{~b}$ it is considered as a splice site mutation (Table 1).

\section{Polymorphisms $(n=5)$}

Relating to FVII deficiency, there are various single nucleotide polymorphisms known in $F 7$ gene, which can lead to an amino acid exchange and have impact on the FVII levels [10]. The investigation of all patients revealed previously described polymorphisms in heterozygous forms concerning 3 patients (patient 2, 5 and 10). The p.R353Q (M1/M2) polymorphism was identified in heterozygous state in patient 2 . The $10 \mathrm{bp}$ promoter insertion of nucleotide -323 (P0/P10) and the polymorphic variation $-122 \mathrm{~T}>\mathrm{C}$ (A1/A2) in the promotor region were found in heterozygous state in 2 patients (patient 2 and 5). The repeat polymorphism of intron 7 was identified in one patient (Table 1).

\section{Discussion}

Some substitutions modified directly or indirectly, the binding of factor VII to tissular factor. In our patients we identified 3 missense mutations the novel p.F328Y and the two reported p.R304Q and p.M298I. The novel p.F328Y involves the substitution of a non polar amino acid (F) by a neutral amino acid (Y) in the catalytic domain of the factor VII which may be affects its affinity in binding to the tissular factor. Using PolyPhen, this substitution is predicted to be probably damaging with a score of 1.000 (sensitivity: 0.00; specificity: 1.00). Others studies demonstrate that the p.F328S mutation reduces tissue factor binding, impairs activation by factor Xa and abolishes the coagulant activities [11,12]. Since our novel mutation p.F328Y occurs in the same position as the reported mutation p.F328S, we hypothesis that the p.F328Y may be plays the same role by the reduction of tissue factor binding. The mutation p.F328S is reported in homozygous state and in compound heterozygous state and it is associated with severe phenotype [2]. In our patient the novel mutation p.F328Y is identified in heterozygous state which may be explain the moderate phenotype.

The reported mutations p.M298I and p.R304Q described in the literature, which occur also in the catalytic domain disrupt interactions between factor VII and tissular factor $[13,14]$.

The p.M298I identified in heterozygous state in our patient (patient 2) and also described with the same state [15], is responsible for an inefficient activation of the 
catalytic site. This mutation is reported in asymptomatic patients when it is in the heterozygous state while in our patient it is associated with epistaxis, dental extraction, gingival and menorrhagia. This may be explained by the presence in heterozygous state of the 3 SNPs; M1M2, P0/P10 $>$ and A1/A2 predicted to reduce the FVII activity [10].

The p.R304Q is reported in homozygous and heterozygous state in many countries indicating that it is a frequent and recurrent mutation [16,17]. In our patient (patient 3) it is associated with homozygous state. Correlation genotype/phenotype for this mutation is in accordance with reported data since this mutation is associated with asymptomatic or paucisymptomatic patients [18], which is the case for our patient who is asymptomatic.

The 2 splicing mutations IVS1a $+5 \mathrm{G}>\mathrm{A}$ and the p.G-39G identified in the heterozygous state respectively in patients 4 and 5 , are associated with hemarthrosis, gingival, menorrhagia and epistaxis: clinical symptoms associated with heterozygous mutations described above $[19,20]$. For the patient 5 the presence of the SNPs A1/A2 known to decrease $25 \%$ of the FVII levels [21] may also has an effect on the phenotype of our patient.

Among the 5 identified mutations, 3 are localized in the exon 8 (catatytic region) which represent the hot spot region of $F 7$ gene as reported in literature [10]. Only the $\mathrm{p}$. R304Q occurred within the CpG dinucleotides.

No mutations were found in 5 patients from 3 unrelated families with reduced FVII activities (2.5\% to $5 \%)$ and they share all the wild alleles in the homozygous state concerning the M1, P0 and A1 SNPs. Only patient number 10 represent 7 repetitions of polymorphism $\mathrm{H}$ in exon 7 which may be responsible for the reduced FVII activity. Others data reported also the absence of molecular defect in some patients in their series [17]. The cause may be an intragenic rearrangement escaping our procedure, so we investigate the use of other techniques such as semi-quantitative multiplex PCR or MLPA.

A unique study described molecular pathology within FVII deficiency in Tunisian patients concern Tunisian Jewish [6]. In this study they identified the p.R304Q mutation which is also present in one of our patients despite their different origin, the p.R304Q is a recurrent mutation known in different ethnics groups and populations. The others mutations described in this study are different from our identified mutations which confirm the Arabic origin of our patients.

A few Tunisian studies were interested in the distribution of some polymorphisms (M1/M2 and P0/P10) in patients with FVII deficiency and healthy groups from different Tunisian regions demonstrate that the most frequent alleles are M1/M1 and P0/P0 in all the studied groups and also in groups from the North of Tunisia $[4,5]$. This distribution is confirmed in our patients who are from the North and in whom we identified only one allele M1/M2 in one patient/7 unrelated patients and we found the allele P0/P10 only in 2 patients. All the others patients are homozygous for the frequent alleles cited above.

\section{Conclusion}

This represents the first comprehensive molecular series of FVII deficiency affected patients in Tunisia. We identified 5 different mutations, one of them is novel. For 5 patients we didn't identify any mutation with PCR/ Sequencing protocol used in this study that's why we investigate other approaches to identify the molecular defects in these patients. Since our patients are from the North province of Tunisia, we will try in the future to continue the molecular study for Tunisian patients from Center and South provinces in order to have a complete idea about the FVII deficiency mutational profile in our country. This allows us to understand the genotype/ phenotype relations of this pathology since it has a heterogeneous clinical manifestation.

\section{Competing interests}

The authors stated that they had no interests which might be perceived as posing a conflict or bias.

\section{Authors' contributions}

$\mathrm{HE}$ performed the research, analyzed the data and wrote the paper; $F B L, W E$, $\mathrm{KZ}$ and $\mathrm{MZ}$ contributed in the data collection; $\mathrm{AJ}$ and RS performed the research; MB, EBAA and GE designed the research. All authors read and approved the final manuscript.

\section{Acknowledgments}

We are grateful to our patients for their help and cooperation. We acknowledge Professor Jayandharan Giridhara Rao for his valuable help and advices.

\section{Author details}

${ }^{1}$ Laboratory of Genetics, Immunology and Human Pathologies, Tunis, Tunisia. ${ }^{2}$ Hemophilia Treatment Center, Aziza Othmana Hospital, Tunis, Tunisia.

Received: 22 June 2012 Accepted: 19 July 2012

Published: 8 August 2012

\section{References}

1. Mariani G, Bernardi F: Factor VII Deficiency. Semin Thromb Hemost 2009, 35:400-406.

2. Herrmann FH, Wulff K, Auerswald G, et al: Factor VII deficiency: Clinical manifestation of 717 subjects from Europe and Latin America with mutations in the factor 7 gene. Haemophilia 2009, 15:267-271.

3. www.whf.org.

4. Nour M, Slama FB, Monastiri K, Hammami M, Helal AN: Prevalence in a Tunisian Arabic population of factor VII DNA variants and relation to factor VIIplasma levels. Clin Chim Acta 2004, 349:199-202.

5. Mtiraoui N, Aboud N, Bouraoui H, Haizem S, Gris JC, Busson M, Tamim H, Almawi WY, Mahjoub T: Reduction in coagulation factor VII plasma levels by $\mathrm{R} 353 \mathrm{Q}$ but not the $-323 \mathrm{P} 0 / 10$ promoter polymorphism in healthy Tunisians. Am J Hematol 2005, 79:11-16.

6. Fromovich-Amit Y, Zivelin A, Rosenberg N, Landau M, Rosa JP, Seligsohn U: Of four mutations in the factor VII gene in Tunisian patients, one novel mutation (Ser339Phe) in three unrelated families abrogates factor $X$ activation. Blood Coagul Fibrinolysis 2005, 16:369-374

7. Barnett R, Larson G: A phenol-chloroform protocol for extracting DNA from ancient samples. Methods Mol Biol 2012, 840:13-19. 
8. Jayandharan GR, Viswabandya A, Nair SC, Chandy M, Srivastava A: Molecular basis of hereditary factor VII deficiency in India: five novel mutations including a double missense mutation (Ala191Glu; Trp364Cys) in 11 unrelated patients. Haematologica 2007, 92:1002-1003.

9. O'Hara PJ, Grant FJ, Haldeman BA, Gray CL, Insley MY, Hagen FS, Murray MJ: Nucleotide sequence of the gene coding for human factor VIl, a vitamin K-dependent protein participating in blood coagulation. Proc Natl Acad Sci USA 1987, 84:5158-5162.

10. Karin W, Falko HH: Twenty Two Novel Mutations of the Factor VII Gene in Factor VII Deficiency. Hum Mutat 2000, 15:489-496.

11. Bharadwaj D, lino M, Kontoyianni M, et al: Factor VII central. A novel mutation in the catalytic domain that reduces tissue factor binding, impairs activation by factor $\mathrm{Xa}$, and abolishes amidolytic and coagulant activity. J Biol Chem 1996, 271:30685-30689.

12. Giansily-Blaizot M, Aguilar-Martinez P, Biron-Andreani C, et al: Analysis of the genotypes and phenotypes of 37 unrelated patients with inherited factor VII deficiency. Eur J Hum Genet 2001, 9:105-111.

13. Girolami A, Berti de Marinis G, Bonamigo E, Vettore S: Similarities and discrepancies in homozygous factor VII defects due to mutations in the region of residues Met298 to Cys310 (exon 8) in the catalytic domain of factor VII. Lab Hematol 2011, 17:17-21.

14. Matsushita T, Kojima T, Emi N, et al: Impaired human tissue factor-mediated activity in blood clotting factor VII Nagoya (Arg304Trp). Evidence that a region in the catalytic domain of factor VII is important for the association with tissue factor. J Biol Chem 1994, 269:7355-7310.

15. Bernardi F, Castaman G, Pinotti M, et al: Mutation pattern in clinically asymptomatic coagulation factor VII deficiency. Hum Mutat 1996, 8:108-112.

16. Girolami A, Bonamigo $E$, Vettore $S$ : The lack of ties between north-eastern Italy and African-Americans suggest a multi-founder effect for FVII Padua (Arg304GIn) disorder. Blood Coagul Fibrinolysis 2010, 21:775-779.

17. Girolami A, BertideMarinis G, Bonamigo E, Allemand E: Worldwide diffusion of FVII Arg304GIn coagulation defect (FVII Padua). Eur J Haematol 2011, 86:135-139.

18. Girolami A, Bertozzi I, de Marinis GB, Bonamigo E, Fabris F: Activated FVII levels in factor VII Padua (Arg304GIn) coagulation disorder and in true factor VII deficiency: a study in homozygotes and heterozygotes. Hematology 2011, 16:308-312.

19. Peyvandi F, Jenkins PV, Mannucci PM, et al: Molecular characterisation and three dimensional structural analysis of mutations in 21 unrelated families with inherited factor VII deficiency. Thromb Haemost 2000, 84:250-257.

20. Ding QL, Wang HL, Wang XF, et al: Double heterozygous mutations of non-canonical splice (IVS1a $+5 \mathrm{~g}>\mathrm{a}$ ) and His348Gln caused inherited coagulation factor VII deficiency. Zhonghua Xue Ye Xue Za Zhi 2004, 25:139-143

21. Kudaravalli R, Tidd T, Pinotti M, Ratti A, Santacroce R, Margaglione M, et al Polymorphic changes in the 5 ' flanking region of factor VII have a combined effect on promoter strength. Thromb Haemost 2002, 88:763-767.

doi:10.1186/1746-1596-7-92

Cite this article as: Elmahmoudi et al:: Identification of genetic defects underlying FVII deficiency in 10 patients belonging to eight unrelated families of the North provinces

from Tunisia. Diagnostic Pathology 2012 7:92.

\section{Submit your next manuscript to BioMed Central and take full advantage of:}

- Convenient online submission

- Thorough peer review

- No space constraints or color figure charges

- Immediate publication on acceptance

- Inclusion in PubMed, CAS, Scopus and Google Scholar

- Research which is freely available for redistribution 